Cerebrovasc Dis 2007:24:156

DOI: $\underline{10.1159 / 000103624}$

\section{Size Criterion for Lacunar Infarction}

\section{Jan Lodder}

Department of Neurology, University Hospital Maastricht, Maastricht, The Netherlands

From their study on lacunar infarct size using diffusionweighted MRI, Cho et al. [1] conclude that the $15 \mathrm{~mm}$ size criteria may no longer be used for lacunar infarction. Although this conclusion may be right, the premises underlying it may not.

First of all Cho et al. used 'positive' criteria to define middle cerebral artery disease and cardioembolism but 'negative' criteria for small vessel disease (absence of middle cerebral artery disease and cardioembolism). The validity of such definition may be questioned. It is obvious that MRA cannot reliably detect small vessel disease (SVD) but cannot exclude it either. Until MRA is validated by a reliable other method, it cannot be used to diagnose or exclude SVD. Therefore, SVD may be present in patients with large vessel disease or cardioembolism, although perhaps less likely.

Second, the authors implicitly suggest that the lacunar hypothesis equals a deep ischemic brain lesion of less than $15 \mathrm{~mm}$ with SVD as its cause, but this would be incorrect. Such lesions are 'usually' caused by the occlusion of a single perforator, leaving room for other causes to be looked for [2]. If such cause is found, oral anticoagulation in case of atrial fibrillation or carotid endarterectomy in case of a high grade internal carotid artery stenosis should not be withheld from such patients $[3,4]$. Size restriction was suggested to make local SVD the most likely cause of a small deep infarct, because it was estimated to correlate with the maximum tissue volume supplied by a single penetrator in most cases. Using MRI, a $20 \mathrm{~mm}$ limit may well be applied instead of $15 \mathrm{~mm}$, and some SVD infarcts may even be larger. However, it seems reasonable to assume that the larger the lesion, the less likely it will be caused by a local occlusion of a single penetrator. So, eventually, I agree with Cho et al. [1] in the sense that 'a grey area of uncertainty' around the cutoff size of $15 \mathrm{~mm}$ for lacunar infarction may be employed, although this agreement is not based on the findings of their study.

\section{KARGER}

Fax +41613061234 E-Mail karger@karger.ch www.karger.com
(C) 2007 S. Karger AG, Basel

1015-9770/07/0241-0156\$23.50/0

\section{References}

1 Cho AH, Kang DW, Kwon SU, Kim JS: Is $15 \mathrm{~mm}$ size criterion for lacunar infarction still valid? A study on strictly subcortical middle cerebral artery territory infarction using diffusion-weighted MRI. Cerebrovasc Dis 2007;23:14-19.

2 Bamford JM, Warlow CP: Evolution and testing of the lacunar hypothesis. Stroke 1988;19:1074-1082.

3 Saxena R, Koudstaal P: Anticoagulants for preventing stroke in patients with nonrheumatic atrial fibrillation and a history of stroke or transient ischaemic attack. Review. The Cochrane Library 2006, issue 4.

4 Naylor AR, Rothwell PM, Bell PRF: Overview of the principal results and secondary analyses from the European and North American randomised trials of endarterectomy for symptomatic carotid stenosis. Eur J Vasc Endovasc Surg 2003;26:115-129.

\section{Jan Lodder}

University Hospital Maastricht, Department of Neurology

PO Box 5800

NL-6202 AZ Maastricht (The Netherlands)

Tel. +31 43387 7060, Fax +31 43387 7055, E-Mail jlod@sneu.azm.nl

\section{Cerebrovasc Dis 2007;24:156-157 \\ DOI: $\underline{10.1159 / 000103625}$}

\section{Reply to the Letter by Lodder: Size Criterion for Lacunar Infarction}

\author{
A-Hyun Cho, Jong S. Kim \\ Department of Neurology, University of Ulsan College of \\ Medicine, Asan Medical Center, Seoul, Korea
}

We appreciate Dr. Lodder's interest in our paper. We agree that we used negative criteria for small vessel disease (SVD). Therefore, we cannot rule out the possibility that SVD may coexist in patients with middle cerebral artery disease (MCAD), internal carotid artery disease (ICAD) or cardiogenic embolism (CE). However, we think that positive criteria for SVD cannot be made with current imaging technologies. Only recently has 7.0-tesla MRI demonstrated individual lenticulostriate arteries in normal subjects [Cho, pers. commun.]. Thus, more advanced technologies will eventually allow us to examine our hypothesis in the 